\title{
Close Approaches of Debris to LARES Satellite During Its First Four Years of Operation.
}

\author{
Claudio Paris ${ }^{(1),(2)}$, Giampiero Sindoni ${ }^{(2)}$, Tommaso di Sabato ${ }^{(3)}$ \\ Museo Storico della Fisica e Centro Studi e Ricerche Enrico Fermi, Via Panisperna 89/a, 00184 Rome, Italy ${ }^{(1)}$ \\ Scuola di Ingegneria Aerospaziale, Sapienza University of Rome, Via Salaria 851, 00138 Rome, Italy ${ }^{(2)}$ \\ Università del Salento, Viale Gallipoli 49, 73100 Lecce, Italy ${ }^{(3)}$
}

\begin{abstract}
Since its launch in February 2012, the LAser RElativity Satellite (LARES) of the Italian Space Agency experienced four close approaches with space debris. LARES orbits at an altitude of $1450 \mathrm{~km}$, in a region where the density of space debris has a peak. However the probability of an impact with a debris during the operational life of the satellite was reasonably low. The analysis of the close approaches identified three of the objects, that are from two peculiar population of objects. This paper discuss the problem of space debris in low orbit, the approaches occurred with LARES, and some possible scenarios related to space regulations and space law in case of an impact.

Key words-General relativity, LARES, satellite laser ranging, space debris, space law.
\end{abstract}

\section{INTRODUCTION}

$\mathbf{T}$ HE Vega launcher first flight (VV01), on 13th February 2012, put LARES (LAser RElativity Satellite) on a circular orbit at $1450 \mathrm{~km}$ of altitude, with $70^{\circ}$ of inclination. The same launch released other eight smaller satellites built by universities [1]; the secondary payloads were released after the upper stage of Vega launcher performed a deorbiting manoeuvre to move on a highly elliptical orbit with a perigee of about $300 \mathrm{~km}$ altitude of altitude. The probability of an impact between LARES and the other objects released during his launch (satellites and upper stage of Vega) was studied before the launch [2]. The elliptical trajectory of the launchrelated object would have brought them periodically close to LARES (within few hundred meters of distance). The analysis showed that since the surface-to-mass ratio of the last stage and of the satellites was much higher than the one of LARES, the rate of change of their apogee altitude would have been high enough that the probability of a collision would have been negligible; indeed the rate of change of LARES altitude has been demonstrated to be very low, about $1 \mathrm{~m} /$ year [3]. The first four years on orbit showed that the risk analysis for the launch-related objects was correct, but four close approaches of other objects showed that there is still a risk of impact with space debris populating the low Earth orbit. A close approach is critical for LARES, since the satellite is completely passive and could not be manoeuvred to change its trajectory and increase the miss distance with a known debris. The investigation of the four events found two peculiar population of space debris which could create future collision risks.

\section{DESCRIPTION OF THE LARES MISSION}

The main scientific objective of LARES mission is the test of the relativistic frame-dragging effect [4], [5], which is manifested of a very small shift of the orbital plane of a satellite. Measuring the effect in the Solar System is tricky because of the condition of week field and low speed involved. The dragging and warping of spacetime is particularly dramatic around massive rotating objects, such as neutron stars, massive rotating black holes, quasars and active galactic nuclei. The recent direct observation of gravitational waves produced by the merging of two spinning black holes [6] highlighted another research field where the confirmation and accurate measurement of the frame-dragging effect is needed. A space mission for testing general relativity using a passive, laser ranged, satellite was proposed in 1989 [7]. The author of the proposal intended to launch a replica of LAGEOS satellite (launched by NASA in 1976) on a supplementary orbit (i.e altitude $6000 \mathrm{~km}$ and inclination of $70^{\circ}$ ), but at the time the LAGEOS 2 mission was almost ready to be launched and its inclination was already decided to be $52^{\circ}$. LAGEOS 2 was launched in 1992 as a joint NASA-ASI (Italian Space Agency) mission. A proposal for a LAGEOS-3 satellites with $70{ }^{\circ}$ of inclination was presented the same year but was not approved [8]. Some years later the LARES mission was proposed, to be launched on a $6000 \mathrm{~km}$ altitude orbit [9]. The high altitude made difficult to found an affordable launch, so an alternative proposal to launch LARES on a $2000 \mathrm{~km}$ of altitude polar orbit was presented [10]; the error budget analysis ruled out the possibility of using such a polar orbit because the unmodelled components of the Earth tidal perturbation were too high to perform a measurement of frame-dragging. In 2004 the application of a new mathematical method to the analysis of the orbital parameters of the two LAGEOS satellites allowed to reach a $10 \%$ accuracy on the measurement of the framedragging effect [11]. The application of the same method to three satellites (the two LAGEOS and LARES) would improve the precision, allowing to reach an accuracy of $1 \%$ [12], [13]. In 2007 ASI funded the LARES mission, and the European Space Agency (ESA) provide the launcher, Vega, which allowed to put the satellite on a circular orbit at 1450 $\mathrm{km}$ of altitude, with an inclination of $64.5^{\circ}$ [14]. In order to minimize the non-gravitational perturbations on the lower orbit, LARES has a high mass-to-surface ratio: the satellite is made of high density $\left(18000 \mathrm{~kg} / \mathrm{m}^{3}\right)$ tungsten alloy [15]. The 
satellite body has been manufactured from a single piece of tungsten alloy, and all the metallic parts (screws, balancing masses and retaining rings) are made of the same material, that has been found being particularly difficult to be machined [16], [17]. An earlier design that was aimed at reducing the thermal thrust perturbation with a partially hollow body [18] was discarded because the satellite would have had a much lower density. The orbit reconstruction is performed using laser ranging data provided by the International Laser Ranging Service (ILRS) [19]. Short duration laser pulses are sent, by about 40 stations of the ILRS, towards the satellite that is covered with 92 Cube Corner Reflectors (CCRs) [20]. Those CCRs reflect the signal back to the emitting station, regardless of the satellite attitude, through three reflections on the back faces. In the case of LARES and the LAGEOS satellites the back faces of the CCRs are uncoated and the laser pulses are sent back by the phenomenon of total internal reflection. The performances of the CCRs, and the thermal interaction with the materials of the satellite, have been verified in a thermo-vacuum facility built for this purpose [21]. The preliminary results of the mission are promising [22], and the design of LARES was successful in minimizing the orbital perturbations, as demonstrated by the very small residual accelerations $\left(0.4 \mathrm{pm} / \mathrm{s}^{2}\right)$ [23]. Fig. 1 shows the satellites used in the LARES experiment.

\section{SPACE DEBRIS AND INTERNATIONAL REGULATIONS}

The result of about 60 years of space operation is a population of thousands objects in the Earth orbit. About 3600 orbiting objects are satellites, but only about 1100 are still operational [24]. In 2016 the US Space Surveillance Network catalogued more than 17000 object in Low Earth Orbit (LEO), of which only 4041 are classified as payloads (both operational and decommissioned) [25]. The catalogued objects, both satellites and tracked debris, receive a NORAD (North American Aerospace Defense Command) number and a COSPAR (Committee on Space Research) number. However, the catalogued objects are only the ones larger than about 5-10 cm in LEO and larger than 30-100 cm on geosynchronous region (GEO). It is assumed the number of objects larger than $1 \mathrm{~cm}$ present in LEO can be between 100000 and 200000; the majority of those smaller debris have been generated by accidental fragmentation of larger objects, such as explosions of fuel tanks on non-operational spacecraft. Two important source of small debris unrelated to fragmentation have been the aluminum oxide $\left(\mathrm{Al}_{2} \mathrm{O}_{3}\right)$ particles released by solid rocket motors firings, and the particles of sodium-potassium coolant (NaK) lost by Russian nuclear powered RORSATs (Radar Ocean Reconnaissance Satellites) when reorbited in disposal orbits at between 700 and $950 \mathrm{~km}$ altitude [26]. Another source of small size (up to few $\mathrm{mm}$ ) debris is the erosion of the surface of satellites, with detachment of coatings and paint flakes, due to the harsh space environment: ultraviolet radiation, atomic oxygen, thermal cycles and micro-particles impacts. Recently an important population of objects with high surface-to-mass ratio has been discovered by the ESA telescope at Tenerife during a survey of the GEO region; the most probable origin of these debris is from thermal covering materials of disposed satellite in the GEO region, driven into highly eccentric orbits by the solar radiation pressure [27]. Collision events have been rare. The first collision between two catalogued objects was recorded in 1996: the French military reconnaissance satellite Cerise was hit by a catalogued debris (COSPAR identification number 1986-019RF) [28]. The debris was generated by the fragmentation of the SPOT 1 Ariane third stage in 1986 [29]. The collision severed the gravity gradient boom of Cerise, generating only one other debris. In 2007 the test of a Chinese anti-satellite weapon destroyed the Chinese decommissioned weather satellite Fengyun-1C, creating the largest cloud of debris in history [30]. In 2009 the communication satellite Iridium 33 and the Russian military satellite Cosmos 2251 impacted, originating more than 2200 fragments [31]. In January 2013 the Russian BLITS (Ball Lens In The Space) scientific laser ranged satellite was destroyed by the impact with one of the debris from the Fengyun-1C fragmentation [32], [33]. In Fig. 2 the density of debris in the LEO region is reported (from [35]): the collisions in 2007 and 2009 are responsible of the higher concentration of debris between $700 \mathrm{~km}$ and $900 \mathrm{~km}$ of altitude. A number of episode of avoided collisions has been recorded. In 2012 the operators of the NASA Fermi Gamma Ray Space Telescope fired the satellite thrusters (that had been in idle for about five years) to avoid a collision with the decommissioned Russian satellite Cosmos 1805 [34]. Space debris proliferation is a risk also for manned missions: from 1999 to 2014 the International Space Station performed 21 avoidance manoeuvres, with a record number of 5 in 2014 [36], [37]. Already in 1978 a worst case scenario was devised: without mitigation actions the progressive increase in the ux of space debris due to the increasing number of space launches will eventually reach a point where each collision between objects in space would generate a cascade effect, further enhancing the number of debris; the enhanced distribution of debris created by the cascade effect could render space activities in LEO infeasible for many tenth of years (the so called Kessler effect) [38]. Even without triggering a Kessler effect, an increased probability of collision will increase the damages to satellite, the costs related to space activities and will pose a serious risk to manned missions. The problem of the proliferation of space debris was assessed early at the beginning of the space age. The first guidelines were issued in 1967 by the United Nations (UN) with the Outher Space Treaty [39]. The article IX of the Treaty states generically that “(...) States Parties to the Treaty shall pursue studies of outer space, including the Moon and other celestial bodies, and conduct exploration of them so as to avoid their harmful contamination (...) and, where necessary, shall adopt appropriate measures for this purpose." Another important statement of the Outer Space Treaty is that both property of and responsibility for any object in the outer space remains of the state that launched it (even if resulted from activities of non-governmental entities): the problem of property in practice can complicate the scenario of any future project for removing space debris [40]. In 1971 the 

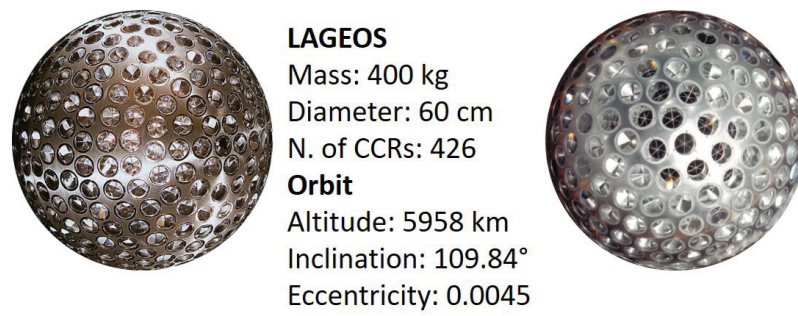

LAGEOS 2

Mass: $400 \mathrm{~kg}$

Diameter: $60 \mathrm{~cm}$

N. of CCRs: 426

Orbit

Altitude: $5951 \mathrm{~km}$

Inclination: $52.64^{\circ}$

Eccentricity: 0.0135
LARES

Mass: $386.8 \mathrm{~kg}$

Diameter: $36.4 \mathrm{~cm}$

N. of CCRs: 92

Orbit

Altitude: $1450 \mathrm{~km}$

Inclination: $64.5^{\circ}$

Eccentricity: 0.0008

Fig. 1. Dimensions and orbits of the satellites used in the LARES experiment

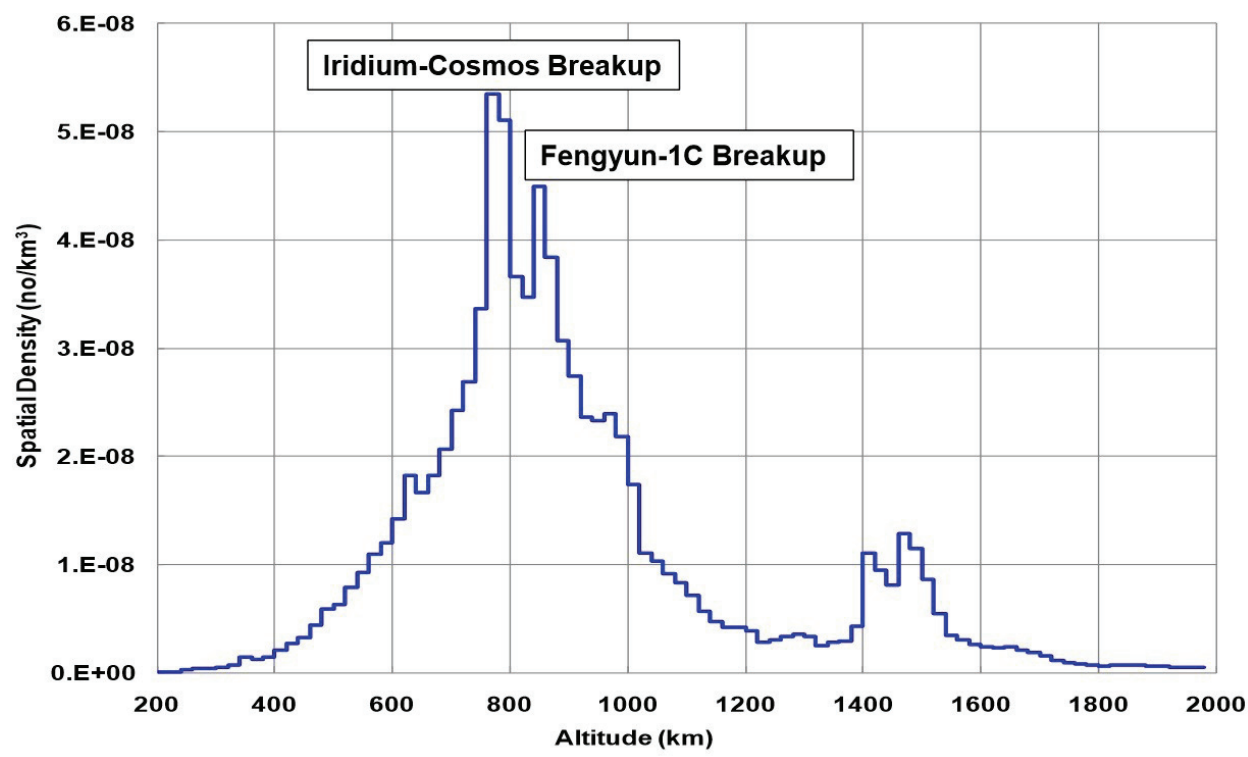

Fig. 2. Debris density in the LEO region [35].

Treaty was improved by the UN Convention on International Liability for Damage Caused by Space Objects (the so called "Liability Convention) [41]. The Convention proposes some guidelines to deal with cases of damages related to space activities. However both the Treaty and the Convention are not binding and, especially during the Cold War and the "space race" era, the proposed measures for reducing the proliferation of debris were not observed. As of 2016, the only case where the Liability Convention was invoked was in 1978, when the Soviet Union's COSMOS 954 military satellite accidentally reentered over Canada, spreading radioactive debris over Canadian territories (the satellite carried a nuclear reactor with about $50 \mathrm{~kg}$ of uranium-235) [42], [43]. The Treaty and the Convention inspired the code of conduits adopted by a number of national space agencies. In 2002 the Inter-Agency Space Debris Committee (IADC), an inter-governmental forum for coordinating the activities of space agencies, developed the first guidelines for the protection of space activities and for the mitigation of space debris. These first guidelines were updated in 2007, after ESA (member of IADC) had already adopted its own Code of Conduit for Space Debris Mitigation [44]. The IADC Space Debris Mitigation Guidelinesby the UN Committee on the Peaceful Uses of Outer Space (COPUOS) as a foundation for developing a series of guidelines, endorsed by UN General Assembly resolution 62/217 of 21 December

\section{$2007[45]$.}

\section{A. ESA debris mitigation regulation}

In 2004 ESA and several other European organization including the Italian Space Agency (ASI), the British National Space Centre (BNSC, from 2010 UK Space Agency), the French Centre national d'ètudes spatiales (CNES) and the German Aerospace Centre (DLR), adopted the European Code of Conduit for Space Debris Mitigation [46], based on the 2002 IADC guidelines [47]. In 2014 the Code of Conduit was replaced by the ISO-24113 requirements [48]. ESA and the national agencies that adopted the Code of Conduit and ISO requirements are applying legal instruments to assure that their contractors (i.e. the owners or manufacturers of any spacecraft launched or funded by any of the above mentioned agencies) are adopting debris mitigation rules. The guidelines require that each space mission shall provide a risk assessment analysis and shall adopt a debris mitigation plan; each design choice for mitigating debris shall be justified. Any intentional or unintentional release of parts on orbit shall be avoided: in particular, the requirements do not allow the use of the so called "yo-yo devices" for reducing the spin of a spacecraft. The end of life of any mission shall be planned: to avoid explosion and fragmentation any space system shall be passivated (fuel tanks drained, tank pressure reduced, batteries 
discharged) before being put out of operation. Two protected region around Earth are defined (Fig. 3):

- a LEO region, from the surface of the Earth up to an altitude of $2000 \mathrm{~km}$;

- a GEO region, a segment of spherical shell with an altitude of $\pm \Delta \mathrm{H}= \pm 200 \mathrm{~km}$ from the GEO orbit, and a latitude of \pm 15 degrees above and below the equator.

In both the regions any space mission shall not operate for more than 25 years: a waiver can be asked only for exceptional and well motivated reasons. At the end of its operational life any spacecraft shall leave the protected region and put on a reentry orbit if in LEO, or moved toward a so called "graveyard orbit" if in GEO (the graveyard orbit shall be some hundred $\mathrm{km}$ above the GEO protected region). The reentry phase from any LEO orbit shall not take more than 25 years: during this phase the launching state is responsible for the safety of the operation ( informing the competent authorities on the reentry time and trajectory to avoid problems with air traffic and maritime traffic). The design of any space system shall minimize the risks connected with the reentry, avoiding any harmful contamination of the Earth environment (avoiding spreading ionising radiation or hazardous biological or chemical products) and limiting the number and size of debris that can reach the ground to a safe level.

\section{B. LARES mission risk assessment and waiver}

The spacecraft design and the orbit of LARES required a careful risk assessment for space debris mitigation in compliance with ESA regulation. At the time of the launch of LARES, the regulation to be adopted were the ones in the European Code of Conduit for Space Debris Mitigation. However, the mission operate in the LEO protected region but could not comply with two requirements of the Code of Conduit:

- SD-DE-09: the de-orbiting measures should be taken into account in the design of the space system;

- SD-OP-03: The operator of a space system should perform disposal manoeuvres at the end of the operational phase to limit the permanent or periodic presence of his space system in the protected regions to a maximum of 25 years.

Indeed because LARES is a passive satellite it is not possible to perform any disposal manoeuvre. Moreover the spacecraft design minimizes the non-gravitational perturbation, while the orbit is on an altitude where the atmospheric drag is already very low: the result is that the altitude of the satellite orbit is lowered of only about $1 \mathrm{~m} /$ year. A natural reentry will not occur before thousands or even hundreds of thousands year. So, for launching LARES a waiver was issued. The waiver was motivated with the scientific requirements and the importance of the scientific target of the mission, and because the position of the satellite will be known with great precision for tens of years since it will be laser tracked (LAGEOS satellite, launched in 1976 on a much higher orbit, is still being tracked by the ILRS). The risk assessment for any unintentional release of debris during launch and mission operation was taken into account during the design phase. The separation system for releasing the satellite was operated by means of non-pyrotechnical actuator and the mechanism was designed to not release any part or fragment when operated. The structure of the satellite is monolithic, and whole spacecraft is composed of very few parts. The CCRs are the only parts that in case of an impact can be damaged and can possibly release small fragment of glass, but a major fragmentation event of the spacecraft is not possible. There are no coatings, paint layers or thermal protection that can be damaged by the space environment and originate small debris. A matter of concern for the mission was the small peak in the density of the debris between $1400 \mathrm{~km}$ and 1600 $\mathrm{km}$ of altitude (see Fig. 2), but the scientific requirements and the launcher capabilities fixed the target altitude at 1450 $\mathrm{km}$, and in any case the probability of an impact at that altitude is anyway low. Indeed the Inter-Agency Space Debris Coordination Committee calculated a probability of less than 2 catastrophic collisions in the next 200 years at the altitude around $1400 \mathrm{~km}$ [50], as showed in Fig. 4.

\section{Close APPROACHES OF ORBITAL DEBRIS TO LARES}

Up to October 2016 four close approaches of space debris to LARES satellite have been registered. The closest approach had an overall miss distance of $142 \mathrm{~m}$. A close approach of a debris to LARES is of a particular concern since it is not possible to perform avoidance manoeuvres. The events are listed in Fig 5 and the characteristic of the objects involved are reported in Table I.

At least three objects were decommissioned satellites. An examination of the events highlighted the presence of two peculiar population of objects that could originate more close approaches in the future. Two encounters (COSMOS 1720 January 23, 2014 and COSMOS 590 May 2, 2015) involved decommissioned satellites of the Strela-1M Soviet/Russian military communication constellation. The Strela-1M system consisted of 370 satellites launched from 1970 to 1992 on a $1500 \mathrm{~km}$ altitude orbit, with an inclination of $74^{\circ}$. The satellites had a mass of about $70 \mathrm{~kg}$ and were powered by batteries that gave about 6 months of operational life. The constellation was refurbished with about one or two launches per year; every launch distributed a group of eight satellites along the orbital plane. The system was finally decommissioned in 1992 [51], [52]. Since the Strela-1M satellites did not have a deorbiting system, the spacecrafts are now debris with a long lifetime, and as their altitude is lowering, some of them will periodically cross the orbit of LARES. The close encounter that occurred on December 26, 2014, involved a debris from a USA Torad Delta 1 (Delta 2310) launcher. The fragmentation of a Delta 300 and Delta 2310 second stages happened with a series of explosions between 1972 and 1977; the fragmentation events released a cloud of more than 500 catalogued debris on almost identical orbits with an altitude of $1500 \mathrm{~km}$ and an inclination of $102^{\circ}$ [53], [54]. As for the Strela-1M satellites, this debris will cross the trajectory of LARES when decaying from their higher orbit. The object that passes close to LARES on July 31, 2015, has a NORAD 


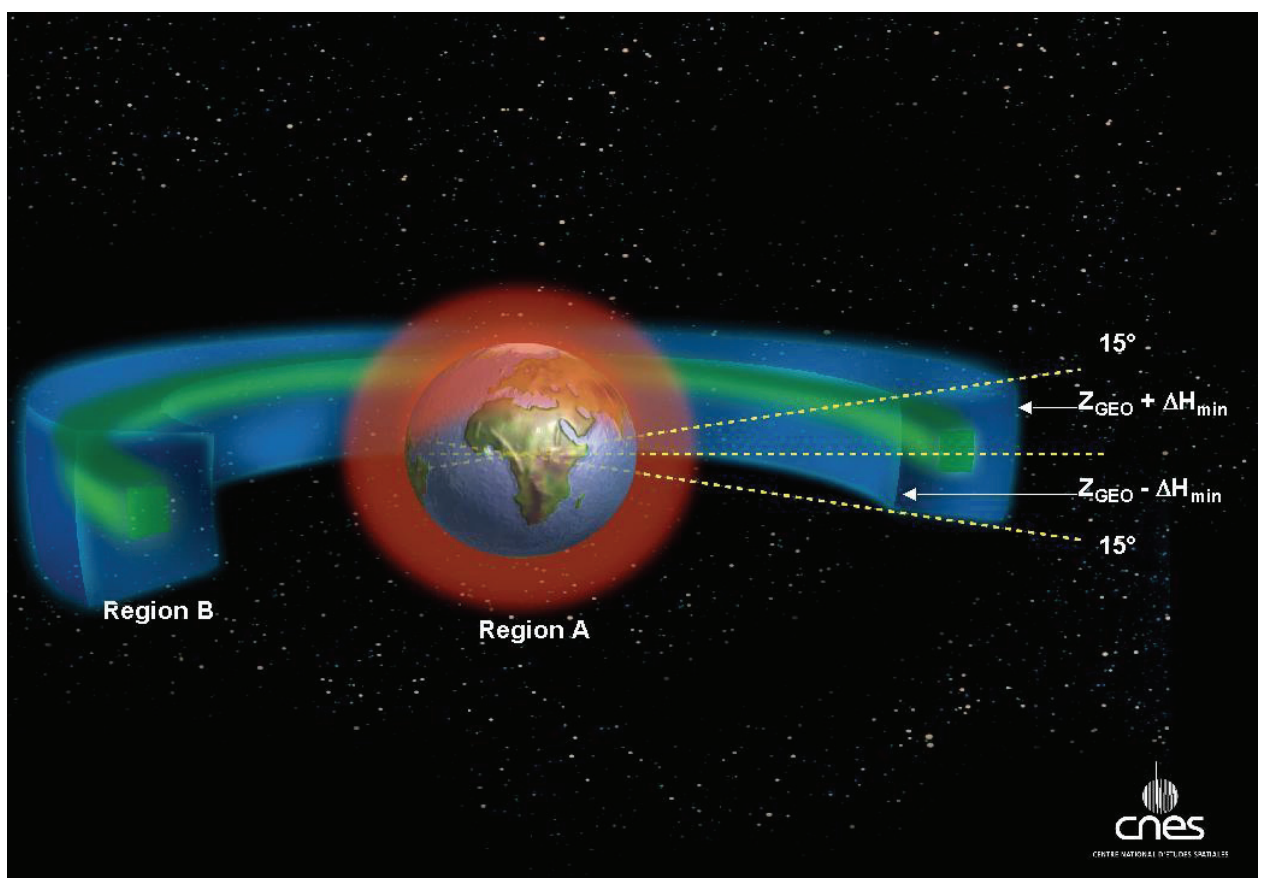

Fig. 3. 3D view of the protected regions defined by IADC guidelines and adopted by the European regulations (from [49]). Region A is the protected LEO region, Region $\mathrm{B}$ is the protected GEO region around the GEO belt (green), $\mathrm{Z}_{\mathrm{GEO}}$ is the altitude of the geostationary orbit.

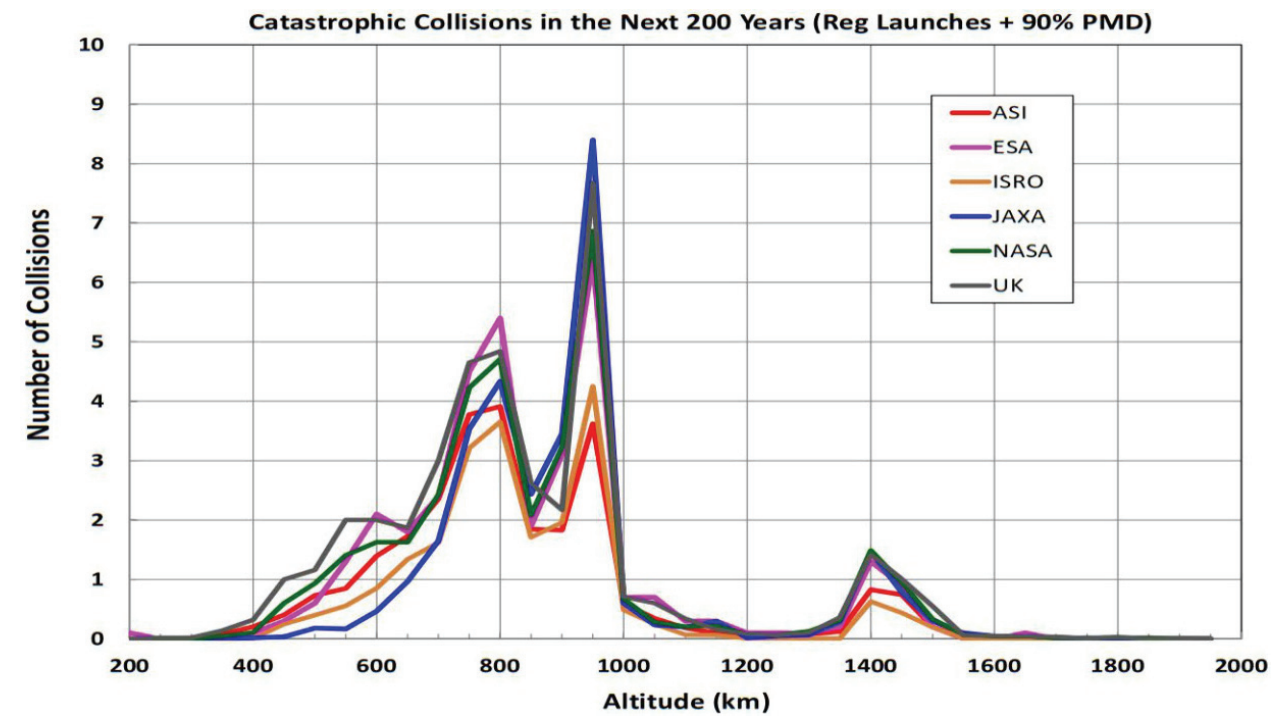

Fig. 4. Probability of catastrophic collision in LEO in the next 200 years provided by several space agencies: ASI, ESA, Indian Space Research Organisation (ISRO), Japan Aerospace Exploration Agency (JAXA), NASA, United Kingdom space agency (from [50]).

identification number but is not catalogued on the COSPAR catalogue. It was not possible to identify its origin.

\section{LEGAL ASPECTS AND POSSIBLE SCENARIOS IN CASE OF IMPACTS}

The UN Outer Space Treaty declares that each country bear international responsibility for its national activities in space (comprising the activities of non-governmental entities, Article VI) and every object launched in the space remains property of the country that launched it (Article VIII), without regard if the object is an active satellite, a malfunctioning satellite or a debris. This situation shall be taken into account by the projects planning to reduce the number of space debris by actively removing the bigger ones, since it will not be possible for any country to remove from the orbit an object owned by another country without an explicit approval. As for 1 January 2016, 104 countries are parties to the Treaty, while other 25 countries have signed it but need to complete the ratification [55]. The effects of an impact of a debris with LARES satellite could be a change of the orbital parameters of LARES and the damage of an unknown number of CCRs. Depending on the number and positions of the 


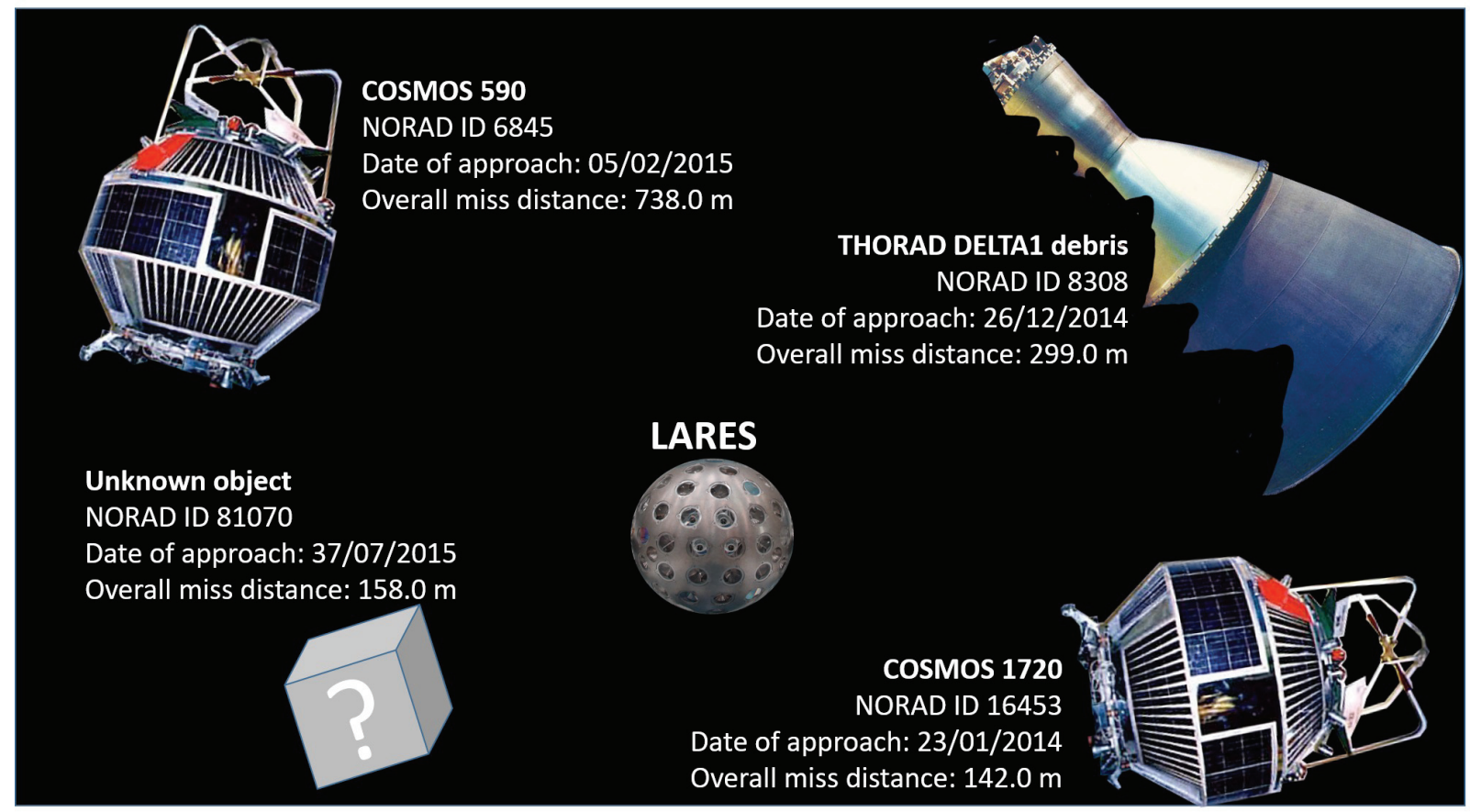

Fig. 5. Summary of the debris that had close approaches to LARES satellite.

TABLE I

CHARACTERISTICS OF THE OBJECTS THAT HAD CLOSE APPROACHES WITH LARES, AND MISS DISTANCES (FROM [56]).

\begin{tabular}{|c|c|c|c|c|}
\hline \multicolumn{5}{|c|}{ Debris characteristics } \\
\hline NORAD ID & 8308 & 81070 & 6847 & 16453 \\
\hline COSPAR ID & $1974-089$ BR & Unknown & $1973-069$ C & $1986-002 \mathrm{E}$ \\
\hline Name & THORAD DELTA 1 DEB & Unknown & COSMOS 590 & COSMOS 1720 \\
\hline Source & US & Unknown & CIS & CIS \\
\hline Period (min) & 115.61 & Unknown & 115.10 & 115.15 \\
\hline Inclination (deg) & 101.89 & Unknown & 74.00 & 73.99 \\
\hline Apogee (km) & 1532 & Unknown & 1487 & 1485 \\
\hline Perigee (km) & 1434 & Unknown & 1433 & 1440 \\
\hline Eccentricity & 0.01 & Unknown & 0.00 & 0.00 \\
\hline Surface/Mass & 0.01 & Unknown & 0.01 & 0.01 \\
\hline Launch Time & $1974-11-15$ & Unknown & $1973-10-02$ & $1986-01-09$ \\
\hline Is Active Satellite & No & Unknown & No & No \\
\hline Time of closest approach & 26 Dec. 2014 & 31 Jul. 2015 & 2 May 2015 & 23 Jan. 2014 \\
\hline \multicolumn{5}{|c|}{ Miss distances } \\
\hline Overall (m) & 299.0 & 158.0 & 738.0 & 142.0 \\
\hline Radial (m) & -188.8 & -150.1 & 116.1 & 21 (primary error: 7) \\
\hline In-track (m) & -32.5 & -16.8 & -329.0 & 114 (primary error: 21) \\
\hline Cross-track (m) & 230.9 & 49.4 & -651.0 & 82 (primary error: 4) \\
\hline
\end{tabular}

damaged CCRs, consequences could be negligible for the mission or at worst could result in the loss of laser return signals from the spacecraft; in the last case LARES would be declared a debris and would be tracked only by the radars of the space surveillance systems. If the impacting object is a decommissioned spacecraft (i.e. a Strela-1M satellite), a cloud of smaller debris could be created as a consequence of the destruction of the spacecraft impacting against the solid tungsten sphere of LARES. The responsibility of the owner of the object shall be demonstrated (and that could not be a 
trivial task). Possible scenarios that can be devised are:

- the nation responsible of the debris ratified the Outer Space Treaty and the UN Liability Convention and the debris is the result of a violation of the guidelines;

- the nation responsible of the debris ratified the Outer Space Treaty and the UN Liability Convention but the debris is not result of a violation of the guidelines or an error in the project planning;

- the nation responsible of the debris ratified the Outer Space Treaty and the UN Liability Convention but the debris is the result of a launch performed before the applicable documents were issued (very unlikely);

- the nation responsible of the debris did not sign the Outer Space Treaty and the UN Liability Convention: very unlikely at the LARES altitude, since the few spacefaring countries that did not ratified the treaty did not appear to have the technology to reach that orbit;

- it will not be possible to determine the origin of the debris (and so the nation responsible for it).

\section{CONCLUSION}

The proliferation of space debris in Earth orbit and the need to protect space activities is being addressed by the international community. The UN Outher Space Treaty and the UN Liability Convention regulate the responsibility of the countries in the case of damages resulting from activities in the outer space. In 2002 the IADC developed the first international guidelines for mitigating space debris, adopted by ESA as a founding for its regulations. Most of the actions of international cooperation are aimed toward monitoring, identifying and cataloguing debris, to share useful information with the international community. Close encounters with space debris are a problem for the LARES mission, since the passive satellite can not perform avoidance manoeuvres. Four close approaches of catalogued space debris with LARES happened from the launch in February 2012 up to October 2016. The investigation on the object that approached to LARES identified two population of debris that could be at risk of other close passes in the future. From the point of view of space law, the aftermath scenarios in case of a collision of LARES with tracked space debris could determine controversies whose solution will not be trivial.

\section{ACKNOWLEDGMENT}

The authors wish to thank the Italian Space Agency for supporting LARES mission under grants I/034/12/0, I/034/12/1, and 2015-021-R.0 and the International Laser Ranging Service for tracking LARES and providing the laser ranging data. C. Paris wish also to acknowledge the support of the Museo Storico della Fisica e Centro Studi e Ricerche Enrico Fermi.

\section{REFERENCES}

[1] A. Paolozzi, I. Ciufolini, A. Gabrielli, C. Paris, G. Sindoni, LARES Mission:Engineering Aspects, XXII AIDAA Conference, Napoli, 9-12 September 2013.

[2] G. Sindoni, I. Ciufolini, F. Battie, A Monte Carlo analysis for collision risk assessment on VEGA launcher payloads and LARES satellite, Artificial Satellites, Vol. 51, No. 1, 4554, 2016.
[3] G. Sindoni, E. C. Pavlis , I. Ciufolini, Orbital Data Analysis on LARES Satellite, AIDAA Congress, Turin, Nov 2015.

[4] I. Ciufolini and J.A. Wheeler, Gravitation and Inertia, Princeton Univ. Press, 1995.

[5] I. Ciufolini, E.C. Pavlis, J.C. Ries, R. Koenig, G. Sindoni, A. Paolozzi and $\mathrm{H}$. Neumayer, Phenomenology of the Lense-Thirring effect in the Solar System: Measurement of frame-dragging with laser ranged satellites, New Astronomy, 17, 341, 2012.

[6] B. P. Abbot, et al. (LIGO Scientific Collaboration and Virgo Collaboration), Observation of gravitational waves from a binary black hole merger, Physical Review Letters 116 (2016) 061102.

[7] I. Ciufolini, A comprehensive introduction to the Lageos gravitomagnetic experiment: from the importance of the gravitomagnetic field in physics to preliminary error analysis and error budget. Int. J. Mod. Phys. A, 4, pp. 3083-3145, 1989.

[8] B.D. Tapley, J.C. Ries, M.M. Watkins, R.J. Eanes, Simulation of an experiment to measure the Lense-Thirring precession using a second LAGEOS satellite, Appendix A of the NASA/University of Texas LAGEOS3 Feasibility Study, B.D. Tapley and I. Ciufolini, Eds., September 1989.

[9] I. Ciufolini, A. Paolozzi, LARES: A New Laser-ranged Satellite for Fundamental Physics and General Relativity, Actual Problems of Aviation and Aerospace Systems, 1, pp. 61-73, 1999.

[10] DM Lucchesi, A. Paolozzi, A cost effective approach for LARES satellite, XVI AIDAA Conference, 2001.

[11] I. Ciufolini and E.C. Pavlis, A confirmation of the general relativistic prediction of the Lense-Thirring effect, Nature, 431, pp. 958-960, 2004.

[12] I. Ciufolini, B. Moreno Monge, A. Paolozzi, R. Koenig, G. Sindoni, G. Michalak, E.C. Pavlis, 2013. Monte Carlo simulations of the LARES space experiment to test General Relativity and fundamental physics. Classical and Quantum Gravity, 30, 235009.

[13] I. Ciufolini, A. Paolozzi, C. Paris, Overview of the LARES Mission: orbit, error analysis and technological aspects. Journal of Physics, Conference Series, 354, p. 1-9, 2012

[14] A. Paolozzi, I. Ciufolini, LARES successfully launched in orbit: satellite and mission description. Acta Astronautica, 91, pp. 313-321, 2013.

[15] A. Paolozzi, I. Ciufolini, C. Paris, G. Sindoni, LARES a new satellite specifically designed for testing general relativity. International Journal of Aerospace Engineering, 2015, p. 1-10, 2015.

[16] A. Paolozzi, I. Ciufolini, C. Vendittozzi, F. Felli, Material and surface properties of lares satellite (conference paper). Proceedings of the 63rd International Astronautical Congress - IAC, pp. 6559-6565, 1-5 Oct 2012, Naples Italy.

[17] A. Paolozzi, I. Ciufolini, F. Felli, A. Brotzu, D. Pilone, Issues on LARES satellite material. 60th International Astronautical Congress, IAC 2009 , pp 5585-5591, Daejeon, Korea; 12-16 October 2009.

[18] A. Bosco, C. Cantone, S. Dell'Agnello, G.O. Delle Monache, M Franceschi, M. Garattini, T. Napolitano et al., Probing gravity in NEO with high-accuracy laser-ranged test masses. International Journal of Modern Physics D, 16, p. 2271-2285, 2007.

[19] M.R. Pearlman, J.J.Degnan, J.M.Bosworth, The international laser ranging service, Adv.Space Res. 30, pp. 135-143, 2002.

[20] I. Ciufolini, D.G. Currie, A. Paolozzi, The LARES Mission for Testing the Dynamics of General Relativity, In: Proceedings of IEEE Aerospace Conference, Big Sky, Montana, USA, 5-12 March 2003, Vol. 2, p. $693-$ 703

[21] A. Paolozzi, I. Ciufolini, C. Paris, G. Sindoni, D. Spano. Qualification tests on the optical retro-reflectors of LARES satellite. Proceedings of 63rd International Astronautical Congress - IAC, pp. 6280-6286, Naples, Italy, 1-5 October, 2012.

[22] I. Ciufolini, A. Paolozzi, E.C. Pavlis, R. Koenig, J. Ries, V. Gurzadyan, R. Matzner, R. Penrose, G. Sindoni, C. Paris,Preliminary orbital analysis of the LARES space experiment, Eur Phys J. Plus, 130:133, 2015.

[23] I. Ciufolini, A. Paolozzi, R. Koenig, E.C. Pavlis, J. Ries, R. Matzner, V. Gurzadyan, R. Penrose, G. Sindoni, C. Paris, Fundamental Physics and General Relativity with the LARES and LAGEOS satellites. Nuclear Physics B-Proceedings Supplements, vol. 243-244, p. 180-193, 2013.

[24] European Space Agency, Protecting space missions. The challenge of space debris, ESA Communications Production, BR-329-ISBN 97892-9221-095-3-ISSN 0250-1589.

[25] NASA Orbital Debris Program Office, Satellite box score, Orbital Debris Quarterly News, p. 13, Vol. 20, Issues 1\&2, April 2016.

[26] D. Mehrholz, L. Leushacke, W. Flury, R. Jehn, H. Klinkrad, M. Landgraf, Detecting, Tracking and Imaging Space Debris, ESA bulletin 109, p. 128, February 2002.

[27] T. Schildknecht, R. Musci, W. Flury, J. de Leon, L. de Fatima Dominguez Palmero, Properties of the high area-to-mass ratio space 
debris population in GEO. 2005 AMOS Technical Conference, Maui, Hawaii, USA, 5-9 September, 2005.

[28] N. Johnson, First orbital collision of catalogued Earth satellites, Orbital Debris Quarterly News, p. 1, Vol 1, Issue 2, September-December 1996.

[29] N.L. Johnson, Preliminary analysis of the fragmentation of the Spot 1 Ariane third stage, Orbital Debris from Upper Stage Breakup (Progress in Astronautics and Aeronautics Vol. 121 ), J. P. Loftus Jr. Eds., chapter 4, American Institute of Aeronautics and Astronautics, September 1989

[30] J. C. Liou and N. L. Johnson, Physical Properties of the Large Fengyun1C Breakup Fragments. Orbital Debris Quarterly News, NASA Orbital Debris Program Office, 12 (2): 5-6. April 2008.

[31] NASA Orbital Debris Program Office, Satellite Collision Leaves Significant Debris Clouds, Orbital Debris Quarterly News, pp. 1-2, Vol. 13 , Issue 2, April 2009.

[32] T. S. Kelso, Chinese space debris hits Russian satellite, AGI Blog, March 8, 2013. URL: http://blogs.agi.com/agi/2013/03/08/ chinese-space-debris-hits-russian-satellite/.

[33] L. David, Russian Satellite Hit by Debris from Chinese AntiSatellite Test, Space.com, March 8, 2013, URL: http://www.space.com/ 20138-russian-satellite-chinese-space-junk.html.

[34] NASA, The Day NASA's Fermi Dodged a 1.5-ton Bullet, Fermi Gammaray Space Telescope news website, April 30, 2013. URL: http://www. nasa.gov/mission_pages/GLAST/news/bullet-dodge.html.

[35] N. Johnson, USA Space Debris Environment, Operations and Policy Updates, 48th Session of the Scientific and Technical Subcommittee Committee on the Peaceful Uses of Outer Space, United Nations 7-18 February 2011.

[36] J.C. Liou, USA Space Debris Environment, Operations and Measurement Updates, 52nd Session of the Scientific and Technical Subcommittee Committee on the Peaceful Uses of Outer Space, United Nations 2-13 February 2015

[37] J. Spark, ISS forced to perform debris avoidance maneuver, Space Safety Magazine, January 13, 2012. URL: http://www.spacesafetymagazine.com/news/ iss-forced-perform-debris-avoidance-maneuver/.

[38] D. J. Kessler and B. G. Cour-Palais, Collision Frequency of Artificial Satellites: The Creation of a Debris Belt. Journal of Geophysical Research, 83, pp. 26372646, 1978.

[39] Treaty on Principles Governing the Activities of States in the Exploration and Use of Outer Space, including the Moon and Other Celestial Bodies (Outer Space Treaty), United Nation General Assembly, resolution 2222 (XXI), 1967.

[40] M. J. Listner, Legal issues surrounding space debris remediation. The Space Review, Monday, August 6, 2012.

[41] Convention on International Liability for Damage Caused by Space Objects (Liability Convention), United Nations General Assembly, resolution 2777 (XXVI), annex, 1971.

[42] E. G. Lee and D. W. Sproule, Liability for Damage Caused by Space Debris: The Cosmos 954 Claim, Canadian Yearbook of international Law/Annuaire canadien de droit international, Volume 26, pp. 273-279, January 1989.

[43] G. Karacalioglu, Energy Resources for Space Missions, Space Safety Magazine, January 16, 2014.

[44] IADC Space Debris Mitigation Guidelines, issued by Steering Group and Working Group 4, IADC-02-01, Revision 1 September 2007.

[45] United Nations General Assembly, International cooperation in the peaceful uses of outer space, resolution 62/217, 22 December 2007.

[46] European Code of Conduct for Space Debris Mitigation, Issue 1.0, June 28, 2004

[47] Committee on the Peaceful Uses of Outer Space, Compendium of space debris mitigation standards adopted by States and international organizations, A/AC.105/C.2/2014/CRP.15, Legal Subcommittee, Fiftythird session, Vienna, 24 March-4 April 2014.

[48] Technical Committee ISO/TC 20, subcommittee SC 14, ISO 24113:2011, Space systems - Space debris mitigation requirements, https://www.iso.org/obp/ui/\#iso:std:iso:24113:ed-2:v1:en, (accessed 15.07.2016)

[49] IADC Working Group 4, Support to the IADC Space Debris Mitigation Guidelines, Action Item 26-2, IADC-04-06, Rev 5.5, May 2014.

[50] Inter-agency space debris coordination committee, Stability of the future LEO environment. Report of an IADC study, 50th Session of the Scientific and Technical Subcommittee Committee on the Peaceful Uses of Outer Space, United Nations, 11-22 February 2013.

[51] A.K. Maini, V. Agrawal, Satellite Technology: Principles and Applications, pp 69-70. John Wiley Sons, 2014.
[52] Encyclopedia Astronautica, Strela-1M, http://www.astronautix.com/s/ strela-1m.html (accessed 15.07.2016).

[53] H. Klinkrad, Space Debris: Models and Risk Analysis, p. 94. Springer Science Business Media, 2006.

[54] D. O. Whitlock, History of on-orbit satellite fragmentation, 13th edition, pp. 100,118, NASA orbital debris program office, May 2004

[55] Committee on the Peaceful Uses of Outer Space, Status of International Agreements relating to activities in outer space as at 1 January 2016, A/AC.105/C.2/2016/CRP.3, Legal Subcommittee, Fifty-fifth session, Vienna, 4-15 April 2016.

[56] G. Sindoni, T. Di Sabato, C. Paris, Space debris close approach to LARES satellite, 2016 IEEE 16th International Conference on Environment and Electrical Engineering (EEEIC), Firenze, Italy, 7-10 June 2016

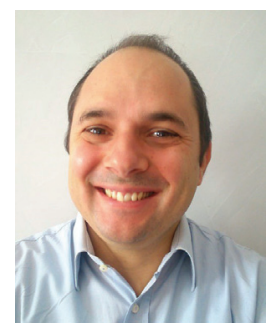

Claudio Paris Received the M.S. degree in aerospace engineering at Sapienza University of Rome, Italy, in 2016, and the Ph.D. degree in aerospace engineering in 2015, at the same University. From 2009 he is member of the team of Sapienza University of the LARES (LAser RElativity Satellite) mission. His research interests include structural health monitoring with fiber optic FBG (Fiber Bragg Grating) sensors and testing microsatellites and small payloads in simulated space environments.

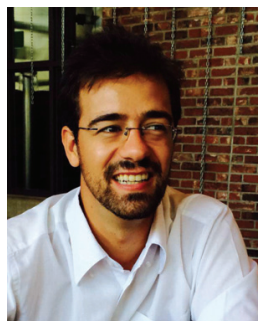

Giampiero Sindoni Giampiero Sindoni completed his $\mathrm{PhD}$ in aerospace Engineering at the "Scuola di Ingegneria aerospaziale" de la "Sapienza" Universit di Roma, in 2009. He is member of the LARES Team of Sapienza University which developed the LAser RElativity Satellite (LARES) and which is performing the data analysis after the successful launch of the satellite in 2012. He is technical responsible of the ISTARC (International Space-Time Analysis Research Centre) where the data analysis of LARES mission is performed. He worked on the flight unit of the Specular Point Like Quick Reference mounted on the International Space Staton and on the relevant ground segment located in Brookline MA USA

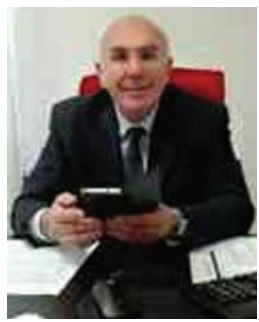

Tommaso di Sabato Tommaso Di Sabato graduated at the University of Bari in Laws of Civil Procedure. Specialized in compensation for damages. He is a member of the Faculty of the University of International Studies of Rome. Author of studies and research project on work organization and human resources management. He is Deputy Director of Human Resources at the University of Salento. 